\title{
EFEITO DA ABRASÃO POR ESCOVAÇÃO NA SUPERFÍCIE DE UM SELANTE DE FÓSSULAS E FISSURAS CONTENDO CLOREXIDINA
}

\author{
Sara de Carvalho Floriano*; Fernanda Miori Pascon; Regina M. Puppin Rontani; Aline R. F. de Castilho
}

\section{Resumo}

Resultados preliminares do nosso grupo de estudo evidenciaram que a incorporação de clorexidina ao selante é um fator de grande contribuição para o controle antimicrobiano sem, no entanto, alterar propriedades mecânicas e biológicas do material selador. Contudo, uma das principais preocupações na caracterização de materiais é o desgaste da superfície, o qual pode comprometer a funcionalidade e longevidade destes na cavidade bucal, influenciando no sucesso do tratamento preventivo e exigindo sua reparação ou substituição. Assim, este estudo in vitro objetiva avaliar o efeito da incorporação de diacetato de clorexidina $(\mathrm{CHX})$ na resistência à abrasão de um selante de fóssulas e fissuras.

\section{Palavras-chave:}

Clorexidina, cimento de ionômero de vidro, abrasão dentária.

\section{Introdução}

CHX é o antimicrobiano mais utilizado e promissor na Odontologia devido sua substantividade, estabilidade e segurança e eficiência clínica (Emilson, 1994).

Estudos recentes evidenciam que a incorporação de $\mathrm{CHX}$ aos diferentes materiais dentários promove a melhoria da atividade antimicrobiana (Duque et., 2017), sem prejuízo para as propriedades mecânicas do material (Castilho et al., 2013).

Os selantes de fóssulas e fissuras atuam como barreira física na superfície dentária, removendo retenções e evitando assim, o acúmulo de restos alimentares e bacterianos nos sulcos oclusais (AAPD, 2016).

O desgaste do selante pode comprometer sua funcionalidade e longevidade na cavidade bucal, influenciando no sucesso do tratamento preventivo (Naaman et al., 2017).

O estudo objetivou avaliar a resistência à abrasão por escovação de um selante de fóssulas e fissuras contendo diacetato de clorexidina em diferentes concentrações.

\section{Resultados e Discussão}

Matrizes de silicona foram utilizadas para preparar espécimes (5 mm x $2 \mathrm{~mm}$; $\mathrm{n}=20$ /grupo) dos seguintes grupos:

- Fluorshield $®$ (Dentsply) + $\mathrm{CHX}$ a 0,1\%

- Fluorshield® (Dentsply) + CHX a 0,2\%

- Fluorshield® (Dentsply) (controle)

Rugosidade Verificada em rugosímetro em velocidade constante de $0,5 \mathrm{~mm} / \mathrm{s}$ e carga de $0,7 \mathrm{mN}$.

Dureza Determinada em durômetro usando penetrador Knoop com carga de $50 \mathrm{~g}$ por $15 \mathrm{~s}$.

Abrasão Os espécimes foram submetidos a 30.000 ciclos de escovação simulada com escova macia e dentifrício diluído, com carga de $200 \mathrm{~g}$.

Novas leituras da rugosidade e dureza foram realizadas após ensaio de abrasão.

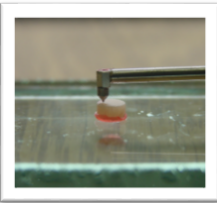

Figura 1. Rugosidade.

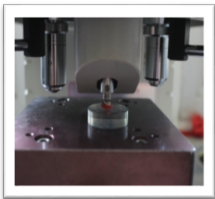

Figura 2. Dureza

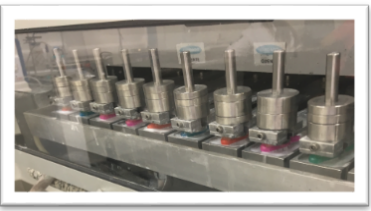

Figura 3. Ciclos de escovação
Tabela 1. Valores de rugosidade de superfície antes e após escovação simulada de selante resinoso contendo ou não clorexidina.

\begin{tabular}{|c|c|c|c|}
\hline GRUPOS & ANTES & DEPOIS & DIFERENÇA \\
\hline CONTROLE & $\begin{array}{l}0.5848 \pm 0.3526 \\
a\end{array}$ & $\begin{array}{l}0.4125 \pm 0.2013 a \\
b^{*}\end{array}$ & 0.2023 \\
\hline $0,1 \% \mathrm{CHX}$ & $\begin{array}{l}0.2004 \pm 0.0867 \\
\mathrm{~b}\end{array}$ & $0.6100 \pm 0.3266 a$ & -0.4096 \\
\hline $0,2 \% \mathrm{CHX}$ & $\begin{array}{l}0.3798 \pm 0.1912 \\
b\end{array}$ & $0.3934 \pm 0.2272 b$ & 0.0414 \\
\hline
\end{tabular}

Tabela 2. Valores de dureza de superfície antes e após escovação simulada de selante resinoso contendo ou não clorexidina.

\begin{tabular}{|l|l|l|l|}
\hline GRUPOS & ANTES & DEPOIS & DIFERENÇA \\
\hline & & & \\
\hline CONTROLE & $13.7814 \pm 5.9988 \mathrm{c}$ & $15.9308 \pm 4.5328 \mathrm{~b}$ & -2.1593 \\
\hline $\mathbf{0 , 1 \%} \mathbf{C H X}$ & $27.3467 \pm 8.2745 \mathrm{a}$ & $20.8878 \pm 4.2580 \mathrm{a}^{*}$ & 6.4589 \\
\hline $\mathbf{0 , 2} \% \mathbf{C H X}$ & $20.0667 \pm 2.8193 \mathrm{~b}$ & $22.0289 \pm 2.6516 \mathrm{a}^{*}$ & -1.9622 \\
\hline
\end{tabular}

Tukey $(p>0,05)$ * representam diferença estatística antes e após a escovação

\section{Conclusões}

A escovação afeta a integridade da superfície do selante de fóssulas e fissuras após a incorporação de clorexidina.

\section{Agradecimentos}

\section{CNPQ}

\section{Referências}

American Academy of Pediatric Dentistry. Use of pit-and-fissure sealants. Ref Manual. 2016;39(6):17-8.

Castilho AR et al. In vitro and in vivo investigation of the biological and mechanical behaviour of resin-modified glass-ionomer cement containing chlorhexidine, J Dent 2013; 41(2): 155-63

Duque $\mathrm{C}$ et al. In vitro and in vivo evaluations of glass-ionomer cement containing chlorhexidine for Atraumatic Restorative Treatment. J Appl Oral Sci. 2017 Naaman R, El-Housseiny AA, Alamoudi. The Use of Pit and Fissure Sealants-A Literature Review. Dent J (Basel). 2017 Dec 11;5(4). pii: E34. 